\title{
Factors influencing smallholder farmer's perspective toward sustainable management of pineapple waste
}

\author{
1,* Ruslan, N.A. and ${ }^{2}$ Saili, A.R.

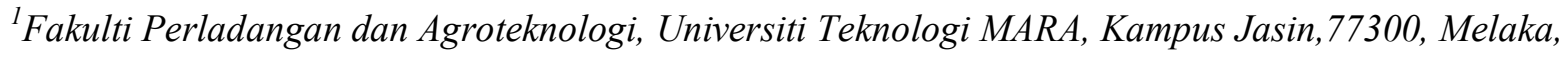 \\ Malaysia \\ ${ }^{2}$ Fakulti Perladangan dan Agroteknologi, Universiti Teknologi MARA Cawangan Sarawak, 93400 \\ Samarahan, Malaysia
}

\section{Article history:}

Received: 15 April 2021

Received in revised form: 8

June 2021

Accepted: 13 November 2021

Available Online: 26

November 2021

Keywords:

Green environment,

Income,

Pineapple waste,

Smallholder farmers,

Sustainable management

DOI:

https://doi.org/10.26656/fr.2017.5(S4).002

\begin{abstract}
Malaysia is one of the world major producers of pineapple. This tropical fruit produces a substantial quantity of by-products such as leaf fibres. These fibres are one of the abundantly available waste materials in Malaysia. They are dumped, left decomposed or even burnt. This paper aimed to identify the factors that influence the perspective of smallholder farmers toward sustainable management of pineapple waste. The study was conducted in Johor among 150 pineapple smallholder farmers. The primary data were collected through a face-to-face interview using a questionnaire. This study employed a random sampling technique by applying the proportionate stratified sampling method, where it ensures the presence of key subgroups within the sample. Descriptive and factor analysis was carried out to analyze the gathered data. From the analysis, four factors were extracted, namely, subjective norms, knowledge, perceived behavioral control and agricultural extension and advisory services. The result provided a platform for smallholder farmers to put more concern towards the utilization of pineapple waste as it provides additional income for smallholder farmers, develop a green environment as well as boost economic growth.
\end{abstract}

\section{Introduction}

Malaysia is a net exporter of pineapples. A pineapple was recorded around $105.2 \%$ in 2019 , for the self-sufficiency level (SSL) which showed a decrease by $0.3 \%$ from 2018. Even though the production of pineapples exceeded the local demand, Malaysia still imports fresh pineapples from nearest countries such as Indonesia and Thailand. The import dependency ratio (IDR) of pineapples in 2019 however, showed an increase of $0.2 \%$ compared to $2014(0.8 \%)$. The per capita consumption (PCC) for pineapple shows a decreasing trend wherein in 2018, the PCC was $7.2 \mathrm{~kg} /$ year as compared to $6.7 \mathrm{~kg} /$ year in 2019.

There are 9 major varieties that are being planted in Malaysia which are N36, Josapine, Yankee, Sarawak, Moris, Moris Gajah, Gandul, Masapine and most recently MD2. N36 and Josapine are cultivars that are locally developed for local fresh fruit and have not been grown outside of Malaysia. The total production of pineapple in 2013 was about 350,000
MT and the Malaysian Pineapple Industry Board (MPIB) aimed to increase the production to become $700,000 \mathrm{MT}$ in 2020. The total area required to accommodate those productions is expected around 23,000 ha and out of 9 varieties, MPIB has chosen MD2 for the industrial planting material.

Pineapple waste is mainly from the selection and elimination of components that are not suitable for human consumption (Upadhyay et al., 2013). According to a study conducted by Cherian et al. (2011), pineapple waste is one of the renewable resources that is easy to find in nature and can be utilized. After the peeling process of pineapple, most of the farmers eliminate a bulk of pineapple waste such as the leaves, stem, and skin. They are just dumped, let decomposed or even burnt, whereas the waste can be fully utilized. The waste can be processed into a new substance that is more useful and has significant value to the economy. According to the Malaysian Pineapple Industry Board (MPIB), pineapple waste can be further processed into charcoal, organic fertilizer, fibreboard, plastic bag, 
paper, animal food and even can be a source of biogas as they undergo anaerobic digestion that sorted municipal solid waste to organic.

The increase in pineapple production will escalate the generation of waste residue and at the same time will cause the rising issues on environmental impact. Roughly, the handling process of the pineapple fruits will produce up to $55 \%$ of waste product (Upadhyay et al., 2013). The previous study highlighted the reason for not managing the pineapple waste is due to the time constraint, availability of limited advanced technology and ignorance from smallholders and local communities regarding the existence of commercial uses of pineapple leaves (Yusof et al., 2015).

Sustainable agriculture is the development that meets the needs of the present without degrading the ability for the future generations to meet their own needs onwards or basically to preserve nature for future generation. Agyeman et al. (2016) defines sustainability as not about environmental concerns only, but it is a wider perspective of social needs, welfare and economic opportunity, which are integrally connected to environmental concerns. Thus, this study was carried out to identify the factors that influence the perspective of smallholder farmers toward sustainable management of pineapple waste.

\section{Materials and methods}

The study was conducted in the southern region of Malaysia, the state of Johor that is the largest area of pineapple cultivations. The study covered all 4 zones in Johor. Table 1 shows the distribution of respondents involved in the study. The table indicates that there are 35 pineapples, smallholder farmers, from Zone 1 and Zone 2 that cover the district of Pontian/Mersing and Simpang Renggam (Kluang) respectively. There are 23 respondents from Zone 3 that cover the district of Batu Pahat and 57 respondents from Zone 4, which cover the district of Muar. The total respondents in this study are 150 pineapple smallholder farmers.

Table 1. Distribution of respondents

\begin{tabular}{clc}
\hline Zone & \multicolumn{1}{c}{ District } & $\begin{array}{c}\text { Number of } \\
\text { respondents }\end{array}$ \\
\hline 1 & Pontian and Mersing & 35 \\
2 & Simpang Renggam (Kluang) & 35 \\
3 & Batu Pahat & 23 \\
4 & Muar & 57 \\
\hline & & 150 \\
\hline
\end{tabular}

This study employed primary data collection that obtained through face-to-face interviews and distribution of questionnaires to gain respondent's information and their perspective toward sustainable management of pineapple waste. Random sampling technique was carried out by applying the proportionate stratified sampling method, where it ensures the presence of key subgroups within the sample. The respondents were comprised of pineapple smallholders who are registered with Malaysian Pineapple Industrial Board (MPIB).

The questionnaires were tested through a pilot study conducted among 30 pineapple smallholder farmers in Johor. The questionnaire was divided into four parts, namely Part A consists of questions related to socio-demographic profile of respondents, Part B consists of questions related to pineapple farming, questions in Part $\mathrm{C}$ asked about factors that influence the perspective of pineapple smallholder farmers and questions in Part D measured respondent's perspective toward sustainable management of pineapple waste. For A five-point Likert scale on a continuum from Strongly Disagree (1) to Strongly Agree (5) was used to indicate the level of respondent's agreement with several statements.

The findings obtained were analysed using descriptive and factor analysis. Descriptive analysis was used to analyse socio-demographic profile of respondents. Next, factor analysis was adopted to extract the factors that influence the perspective of pineapple smallholder farmers toward sustainable management of pineapple waste. Factor analysis was conducted using the principle component method and relevant factors were extracted by varimax method. The number of factors to be extracted will be based on eigenvalue for each factor, which it had to be equal to or greater than one.

\section{Results and discussion}

\subsection{Descriptive analysis}

Descriptive analysis is used to describe the sociodemographic profile of respondents such as age, income, education level, farm size and experience. Table 2 shows the demographic profile of the 150 pineapple smallholder farmers in the study area. The finding indicates that majority of the pineapple smallholder farmers are male $(93.3 \%)$ while only $6.7 \%$ are female. The highest category of respondent's ages is between $30-39$ years old $(28.7 \%)$ and only $8.7 \%$ of the respondent's ages between $20-29$ years old. Besides that, most of the pineapple smallholder farmers have income ranged between RM 1,001 - RM $3,000(51.3 \%)$ while only smaller percentage of them that have an income above RM 5,001 (5.3\%). In this study, the percentage of respondents who have a farm 
size less than 10 acres are $76.0 \%, 2.70 \%$ of the respondents have more than 41 acres and only $2.0 \%$ of them have a farm size between $31-41$ acres. Moreover, most of the pineapple smallholder farmers have experience less than 10 years in planting pineapple $(58 \%) .55 .3 \%$ of the respondents had gone through secondary education, with only a small number of respondents with no formal education $(8.0 \%), 20.7 \%$ had completed with primary education and $16.0 \%$ had graduated with tertiary education (diploma and degree holders). Furthermore, majority of the pineapple smallholder farmers planted varieties Josaphine $(44.0 \%)$ at their farm and followed by varieties Moris (41.3\%).

Table 2. Demographic profile of respondents

\begin{tabular}{|c|c|c|}
\hline Characteristics & $\begin{array}{l}\text { Frequency } \\
(\mathrm{N}=150)\end{array}$ & $\begin{array}{l}\text { Percentage } \\
(\%)\end{array}$ \\
\hline \multicolumn{3}{|l|}{ Gender } \\
\hline Male & 140 & 93.3 \\
\hline Female & 10 & 6.7 \\
\hline \multicolumn{3}{|l|}{ Age (years) } \\
\hline $20-29$ & 13 & 8.7 \\
\hline $30-39$ & 43 & 28.7 \\
\hline $40-49$ & 38 & 25.2 \\
\hline $50-59$ & 34 & 22.7 \\
\hline Above 60 & 22 & 14.7 \\
\hline \multicolumn{3}{|l|}{ Income (RM) } \\
\hline$<1,000$ & 16 & 10.7 \\
\hline $1,001-3,000$ & 77 & 51.3 \\
\hline $3,001-5,000$ & 49 & 32.7 \\
\hline$>5,001$ & 8 & 5.3 \\
\hline \multicolumn{3}{|l|}{ Farm size (acres) } \\
\hline$<10$ & 114 & 76 \\
\hline $11-20$ & 19 & 12.7 \\
\hline $21-30$ & 10 & 6.7 \\
\hline $31-40$ & 3 & 2.0 \\
\hline$>41$ & 4 & 2.7 \\
\hline \multicolumn{3}{|l|}{ Experience (years) } \\
\hline$<10$ & 87 & 58 \\
\hline $11-20$ & 35 & 23.3 \\
\hline $21-30$ & 18 & 12.0 \\
\hline $31-40$ & 5 & 3.3 \\
\hline$>41$ & 5 & 3.3 \\
\hline \multicolumn{3}{|l|}{ Education level } \\
\hline No formal education & 12 & 8.0 \\
\hline Primary education & 31 & 20.7 \\
\hline Secondary Education & 83 & 55.3 \\
\hline Tertiary education & 24 & 16.0 \\
\hline \multicolumn{3}{|c|}{ Varieties of pineapple planted } \\
\hline Moris & 62 & 41.3 \\
\hline Josaphine & 66 & 44.0 \\
\hline Maspine & 2 & 1.3 \\
\hline Yankee & 1 & 0.7 \\
\hline MD2 & 19 & 12.7 \\
\hline
\end{tabular}

\subsection{Factor analysis}

Factor analysis was used to uncover the latent factors that influence the perspective of pineapple smallholder farmers toward sustainable management of pineapple waste. There were 16 statements to measure the factors affecting respondents' perspective towards sustainable management of pineapple waste in the questionnaire and principle component analysis (PCA) was carried out to examine the validity of the statements. The Kaiser-Meyer-Olkin (KMO) sampling adequacy and Bartlett's test of sphericity were used to measure the presence of correlation among the variables, which is ranging from 0 to 1 and should be greater than 0.6 to confirm the appropriateness of conducting factor analysis (Hair et al., 1998). Small values for KMO indicate that the factor analysis of the variables may not be appropriate, since the correlations between the variables cannot be explained by the other variables (Norusis, 1993). KMO test also measure the proportion of the total variation in the dependent variable that is explained by independent variables. Based on Table 3, the result shows that the KMO value was 0.727 indicating inter-correlations between the factors, whereas Bartlett's test of sphericity was significant $(\mathrm{p}<0.01)$.

Table 3. Kaiser-Meyer-Olkin and Bartlett's Test of Sphericity

\begin{tabular}{llc}
\hline $\begin{array}{c}\text { Kaiser-Meyer-Olkin measure of sampling } \\
\text { adequacy }\end{array}$ & 0.727 \\
\hline Bartlett's test of & Approx. chi-square & 1199.929 \\
sphericity & $d f$ & 171 \\
& Sig. & 0.000 \\
\hline
\end{tabular}

\subsection{Factors that influence respondents' perspective toward sustainable management of pineapple waste}

Table 4 indicates the summary of factor analysis results. Based on the analysis, four factors were extracted from the 16 statements as well as the factor loadings, eigenvalues and variance. The factors loading for standardized statements in this study were in the range of $0.552-0.850$. According to the results of rotated factor matrix, only item with factor loading of 0.5 and above were considered as significant statements. Furthermore, factors that have eigenvalues more than 1 are considered significant and vice versa. The total variance explained in this study was $57.683 \%$. The 4 factors that were extracted from the analysis namely subjective norms, knowledge, perceived behavioral control and agricultural extension and advisory services. These 4 factors are summarized as follows:

Factor 1 - The subjective norm was recognized as 
Table 4. Summary of factor analysis results

Factor Loading

Items $\mathrm{F}_{1} \mathrm{~F}_{2} \mathrm{~F}_{3} \mathrm{~F}_{4}$

Factor 1 : Subjective Norms

- Environmental influences me to manage pineapple waste.

0.850

- Influence of family members in decision making to manage pineapple waste.

0.822

- Other farmers influence me in managing pineapple waste.

0.813

- Government policy encourage me to manage pineapple waste.

0.770

Variance (percent explained)

24.578

Factor 2: Knowledge

- Pineapple waste such as the outer skin can be used as feed for ruminants.

0.779

- Money and energy lost can be reduced through the best way of management.

0.773

- I know that pineapple waste can be used in producing new products.

0.666

- Pineapple waste can be processed into organic fertilizer.

- I have knowledge in managing pineapple waste.

- I gain sufficient knowledge from exhibition organized by MPIB.

0.552

Variance (percent explained)

17.698

Factor 3: Perceived Behavioural Control

- High cost is needed in managing the pineapple waste.

0.834

- Modern technology is required in managing the pineapple waste.

0.791

- Management of pineapple waste requires a hand-on and practical training.

0.745

Variance (percent explained)

8.008

Factor 4: Agricultural Extension and Advisory Services

- I am able to manage pineapple waste with proper facility and equipment is

- The agricultural extension officer is very helpful and knowledgeable.

- I am willing to join any training programme related to management of pineapple waste.

the first factor that influenced the respondents' perspective towards sustainable management of pineapple waste. This factor consists of five subvariables and has a total variance of 24.578 percent. Environmental influences me to manage pineapple waste has the highest factor loadings (0.850), followed by influence of family members in decision making to manage pineapple waste (0.822), other farmers influence me in managing pineapple waste (0.813) and government policy encourage me to manage pineapple waste (0.770). The result of this factor implies that the smallholder farmers tend to have positive perspective toward sustainable management of pineapple waste with the influence of people who close to them and can influence their decision making.

Factor 2 - The second factor is knowledge, which has a total variance of 17.698 percent and comprises of six sub- variables; outer skin can be used as feed for ruminants with the highest factor loadings (0.779), followed by money and energy lost can be reduced through the best way of waste management (0.733), I know that pineapple waste can be used in producing new products (0.666), pineapple waste can be processed into organic fertilizer (0.619), I have knowledge in managing pineapple waste (0.559) and I gain sufficient knowledge from programme organized by MPIB (0.552). With efficient and appropriate knowledge, the smallholder farmers are more likely to have positive perspective toward sustainable management of pineapple waste.

Factor 3 - The third factor is perceived behavioral control, which has a total variance of 8.008 percent and comprises of three-sub-variables. High cost is needed in managing the waste has the highest factor loadings (0.834), followed by modern technology is required in management of pineapple waste (0.791) and management of pineapple waste requires a hand-on and practical training (0.745). The result suggests that pineapple smallholder farmers tend to accept new idea/concept or innovation if they have enough resources or facilities to implement and perform. Perceived behavioral control is the factor that facilitates certain behavior or more difficult to 
perform.

Factor 4 - Agricultural extension and advisory services is the fourth factor with the total variance of 7.398 percent and comprises of three-sub variables. $I$ am able to manage pineapple waste with the availability of proper facility and equipment has the highest factor loadings (0.663), followed by the agricultural extension officer is very helpful and knowledgeable (0.622) and I am willing to join any training programme related to management of pineapple waste (0.621). Pineapple smallholder farmers tend to have positive perspective toward sustainable management of pineapple waste with the appropriate assistance and guidance from agricultural extension officer and advisory services.

\subsection{Reliability analysis}

Table 5 shows the result of reliability test and Cronbach's alpha score was used to measure the internal reliability consistency significance of 16 relevant statements. Four latent factors were extracted from factor analysis and have sufficient internal reliability consistency as indicated by Cronbach's alpha scores, as shown in Table 4. The coefficient value of Cronbach's alpha lies between 0 until 1 and the higher the coefficient value indicates that more relevant the variables in this factor. According to the study conducted by Nunnally and Bernstein (1994), the recommended coefficient value that is used to accept the decision of the reliability analysis is 0.7 and above while Bagozzi and Yi (1988) decided on 0.6 and above as a benchmark of acceptance. However, according to Hair et al. (1998), the coefficient values are also at acceptable level as they are all above 0.5. Table 4 indicates that the Cronbach's alpha values for all four factors were above 0.5 . The finding shows that all factors derived from factor analysis were acceptable and reliable as a coefficient value is above 0.5 and 0.7 or higher indicates a sufficient internal reliability consistency.

Table 5. Result of reliability test

\begin{tabular}{lcc}
\hline Factors & $\begin{array}{c}\text { Cronbach's } \\
\text { Alpha Score }\end{array}$ & $\begin{array}{c}\text { Number of } \\
\text { items }\end{array}$ \\
\hline Subjective norms & 0.855 & 4 \\
Knowledge & 0.784 & 6 \\
Perceived behavioral control & 0.805 & 3 \\
Agricultural extension and & 0.563 & 3 \\
\hline
\end{tabular}

\section{Conclusion}

The ultimate objective of this study was to identify the factors that influence the perspective of pineapple smallholder farmers toward pineapple waste. Factor analysis was carried out to analyze the gathered data. From the analysis, four factors were extracted, namely subjective norms, knowledge, perceived behavioral control and agricultural extension and advisory services.

Subjective norms were recognized as the major factor that influences the perspective of smallholders toward sustainable management of pineapple waste. The finding indicates that smallholder farmers tend to accept new practice or innovation at their farm when they have strong influence from people surrounding them such as family member, spouse, friends and neighbor. Besides that, knowledge was identified as the second factor that influence respondents to have positive perspective towards sustainable management of pineapple waste. Knowledge is the main aspect that will influence the decision making of respondents. The result shows that a knowledgeable pineapple smallholder farmer tends to manage pineapple waste sustainably.

Furthermore, factor analysis was extracted perceived behavioral control as the third factor that significantly influences the respondent's perspective towards sustainable management of pineapple waste. The finding suggests that with the availability of modern technology and facilities, pineapple smallholder farmers will likely have positive perspective towards sustainable management of pineapple waste. They feel comfortable to perform certain practice at farm with enough availability of resources. Lastly, agricultural extension and advisory services was identified as the fourth factors that have significantly influences on respondent's perspective. The support from them is required in order to facilitate smallholders in increasing farm productivity and improving farm management practices. With the appropriate assistance from advisory services and good relationship with agricultural extension, smallholder farmers tend to have positive perspective thus will likely manage pineapple waste sustainably.

The sustainable management of pineapple waste is very important issues to be addressed since it can increase the income of smallholder farmers, improve their livelihood, reduce environmental impact and conserve natural resources.

\section{Conflict of interest}

The authors declare no conflict of interest.

\section{Acknowledgments}

This research article funded by Research Grant LESTARI "Sustainable Management of Pineapple Waste: Perspective of Smallholders" 600-IRMI/ 
DANA 5/3/LESTARI (0073/2016).

\section{References}

Agyeman, J., Schlosberg, D., Craven, L. and Matthews, C. (2016). Trends and Directions in Environmental Justice: From Inequity to Everyday Life, Community, and Just Sustainability. Annual Review of Environment and Resources 41, 321-340. https:// doi.org/10.1146/annurev-environ-110615-090052

Bagozzi, R.P. and Yi, Y. (1988). On the Evaluation of Structural Equation Models. Journal of the Academy of Marketing Science, 16(1), 74-94. https:// doi.org/10.1007/BF02723327

Cherian, B.M., Leo, A.L., De Souza, S.F., Costa, L.M.M., De Olyveira, G.M., Kottaisamy, M. and Thomas, S. (2011). Cellulose nanocomposites with nanofibres isolated from pineapple leaf fibers for medical applications. Carbohydrate Polymers, 86(4), $1790 \quad-\quad 1798 . \quad$ https://doi.org/10.1016/ j.carbpol.2011.07.009

Hair, J.F. Jr. anderson, R.E., Tatham, R.L. and Black, W.C. (1998). Multivariate Data Analysis. $5^{\text {th }}$ ed. Upper Saddle River, New Jersey, USA: Prentice Hall.

Norusis, M.J. (1993). SPSS for Windows Professional Statistics Release 6.0. Chicago, USA: SPSS Inc.

Nunnally, J.C. and Bernstein, I.H. (1994) Psychometric theory. 3rd ed. New York, USA: McGraw-Hill, Inc.

Upadhyay, A., Lama, J.P. and Tawata, S. (2013). Utilization of Pineapple Waste: A Review. Journal of Food Science and Technology Nepal, 6, 10-18. https://doi.org/10.3126/jfstn.v6i0.8255

Yusof, Y., Yahya, S.A. and Adam, A. (2015). Novel Technology for Sustainable Pineapple Leaf Fibers Productions. Procedia CIRP, 26, 756-760. https:// doi.org/10.1016/j.procir.2014.07.160 